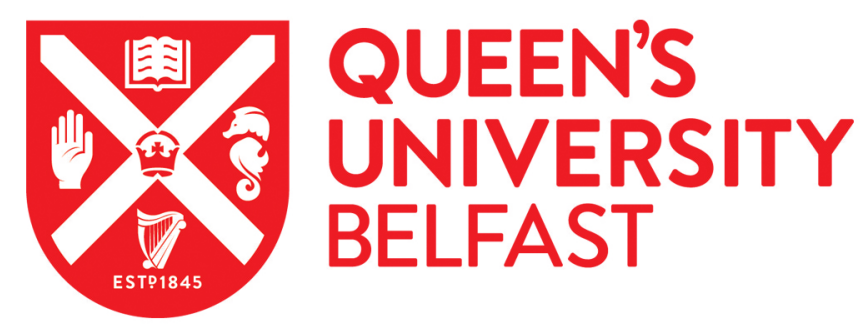

\title{
Strategies for living well with hormone-responsive advanced prostate cancer-a qualitative exploration
}

Matheson, L., Nayoan, J., Rivas, C., Brett, J., Wright, P., Butcher, H., Jordan, P., Gavin, A., Glaser, A., Mason, M., Wagland, R., \& Watson, E. (2020). Strategies for living well with hormone-responsive advanced prostate cancer-a qualitative exploration. Supportive Care in Cancer. https://doi.org/10.1007/s00520-020-05594-8

Published in:

Supportive Care in Cancer

Document Version:

Peer reviewed version

Queen's University Belfast - Research Portal:

Link to publication record in Queen's University Belfast Research Portal

Publisher rights

(๖) 2020 Springer Nature Switzerland AG. Part of Springer Nature.

This work is made available online in accordance with the publisher's policies. Please refer to any applicable terms of use of the publisher.

\section{General rights}

Copyright for the publications made accessible via the Queen's University Belfast Research Portal is retained by the author(s) and / or other copyright owners and it is a condition of accessing these publications that users recognise and abide by the legal requirements associated with these rights.

Take down policy

The Research Portal is Queen's institutional repository that provides access to Queen's research output. Every effort has been made to ensure that content in the Research Portal does not infringe any person's rights, or applicable UK laws. If you discover content in the Research Portal that you believe breaches copyright or violates any law, please contact openaccess@qub.ac.uk. 
Title: Strategies for living well with hormone-responsive advanced prostate cancer - a qualitative exploration

Lauren Matheson 1 , Jo Nayoan ${ }^{2 *}$, Carol Rivas ${ }^{2 * *}$, Jo Brett ${ }^{1}$, Penny Wright ${ }^{3}$, Hugh Butcher ${ }^{4}$, Paul Jordan ${ }^{4}$, Anna Gavin ${ }^{5}$, Adam Glaser ${ }^{36}$, Malcolm Mason ${ }^{7}$, Richard Wagland ${ }^{2 *}$ \& Eila Watson ${ }^{1 *}\left({ }^{*}\right.$ joint last authors)

\section{Affiliations}

1 Oxford School of Nursing and Midwifery, Oxford Brookes University, Oxford, OX3 OFL, United Kingdom (UK)

${ }^{2}$ Faculty of Health Sciences, University of Southampton, Southampton, SO17 1BJ, UK

${ }^{3}$ Leeds Institute of Medical Research at St James's, University of Leeds, Leeds, UK

${ }^{4}$ LAPCD patient user advisory group, Leeds, UK

${ }^{5}$ Northern Ireland Cancer Registry, Centre for Public Health, Queen's University Belfast, Belfast, BT12 6BJ, UK

${ }^{6}$ Leeds Institute of Data Analytics, University of Leeds, Leeds, LS2 9JT, UK

${ }^{7}$ Cardiff University, CF14 2TL

Running title: Living well with advanced prostate cancer

*different current address

* European Centre for Environment and Human Health (ECEHH), University of Exeter, Truro ,TR1 3HD, UK

** Department of Social Science, University College London (UCL), London, WC1H ONR, UK

Key words: Patient experience, advanced, metastatic prostate cancer, health care, quality of life, qualitative

Corresponding author: Professor Eila Watson, Oxford School of Nursing and Midwifery, Faculty of Health and Life Sciences, Oxford Brookes University, Jack Straws Lane, Oxford OX3 OFL, 01865 482665, ewatson@brookes.ac.uk

Acknowledgements: The authors thank all the men who responded to the survey. We thank the Movember Foundation, in partnership with Prostate Cancer UK, for funding the study. We acknowledge the following people for their contribution to the development, setting up and running of the study: Rebecca Mottram, Majorie Allen, Heather Kinnear, Conan Donnelly, Oonagh McSorley, Victoria Cairnduff, Linda Roberts, Adrian Slater, Picker Institute Europe, the LAPCD User Advisory Group and Clinical and Scientific Advisory Group. This study is based in part on information collected and quality assured by the National Cancer Registration and Analysis Service (part of Public Health England), the Northern Ireland Cancer Registry, the Welsh Cancer Intelligence \& Surveillance Unit and the Scottish Cancer Registry (part of the Public Health \& Intelligence Unit of NHS National Services 
Scotland). The work of cancer registries uses data provided by patients and collected by health services as part of their care and support. 


\section{Abstract}

Purpose: Due to recent treatment advances, men are increasingly living longer with advanced prostate cancer ( $\mathrm{PCa}$ ). This study sought to understand men's experiences of living with and adjusting to advanced hormone-responsive PCa, and how this influenced their quality of life (QoL), in order to highlight how support could be optimised.

Methods: Participants were recruited through a UK wide survey- the 'Life After Prostate Cancer Diagnosis' study. In-depth telephone interviews were conducted with 24 men (aged 46-77 years) with advanced (stage IV) hormone-responsive PCa diagnosed 18-42 months previously. Thematic analysis was undertaken using a framework approach.

Results: Most participants perceived their QoL to be relatively good, which was influenced by the following factors (enablers to 'living well' with $P C a$ ): a sense of connectedness to others, engagement in meaningful activities, resources (social, cognitive, financial), ability to manage uncertainty, utilisation of adjustment strategies and support, communication and information from health professionals. Barriers to 'living well' with PCa were often the converse of these factors. These also included: more troublesome PCa-related symptoms, and stronger perceptions of loss and restriction.

Conclusions: In our study, men living with advanced hormone-responsive PCa often reported a good QoL. Exploring the influences on QoL in men with advanced PCa indicates how future interventions might improve the QoL of men who are struggling. Further research is required to develop and test interventions that enhance QoL for these men.

\section{Introduction}

Prostate cancer (PCa) is the second most common cancer amongst men globally [1]. In the UK, 15$26 \%$ of cases will be diagnosed with advanced PCa (stage IV) of whom $30 \%$ will survive for at least 5 years [1,2]. Men with advanced PCa are usually offered androgen deprivation therapy (ADT), with or without chemotherapy, or if they are unfit, watchful waiting [3]. Recent treatment advances can potentially increase survival [4], so this population of men are living longer with advanced PCa. However, treatments such as ADT can lead to a substantial symptom burden and negatively impact quality of life (QoL) [5,3]. Men on ADT have a 41\% increase risk of depression [6] and those with advanced PCa, regardless of treatment type, are also at greater risk of suicide compared to men with earlier stage disease $[7,8]$. Previous studies have focused on the challenges men face with regards to ADT side-effects, which can include emotional instability, lowered libido, sexual dysfunction, fatigue, gynecomastia, hot flushes [5,3] as well as dissatisfaction over body feminisation [9]. However, little previous research has focused on the strategies men adopt to manage these impacts and how men perceive their QoL and wellbeing.

Our previous metasyntheses of qualitative literature illustrated men with advanced PCa can experience uncertainty, loss and isolation, feel physically restricted and lament altered career plans and a disrupted future [10-14]. However, previous qualitative research on men with advanced PCa is either focused specifically on symptoms $[15,16,10]$, spirituality [17] decision making [12] or conducted with men 'close to death' [18] or with castrate-refractory PCa $[19,20,10]$. Few studies 
$[11,21]$ have explored men's coping or adjustment strategies to living with advanced PCa and particularly the impact of disease and treatment related challenges. Given the increasing numbers of men with advanced PCa living longer and in a hormone-sensitive phase, this is a significant information gap [4].

The Life After Prostate Cancer Diagnosis (LAPCD) study [22], a UK population-based study aimed to explore the impact of PCa on men's well-being through a survey and interviews. Given the dearth of studies on men living with advanced PCa, we aimed to explore the experiences of all interviewees living with stage IV hormone-responsive $\mathrm{PCa}$, drawn from the total sample of interviewed men. We also aimed to explore the influences on their perceived QoL and to highlight how support services could be optimised, as few interventions have addressed the needs of this growing population of men.

\section{Methods}

Ethics

Ethical and regulatory approvals for the LAPCD study were obtained from Newcastle/North Tyneside Research Ethics Committee (15/NE/0036), Health Research Authority Confidentiality Advisory Group (15/CAG/0110), NHS Scotland Public Benefit and Privacy Panel (0516-0364), Northern Ireland Research Ethics Office (16/NI/0073). Informed consent was obtained.

\section{Design}

Full methodological details for the LAPCD study have been published previously [22]. Men alive 1842 months following PCa diagnosis (ICD10 C61) were identified through population-based cancer registries in England, Wales, Scotland and Northern Ireland, and mailed surveys from their treating Trust/Board. Completed surveys were returned to a survey provider, Picker Institute Europe, who managed the data. Men in England were surveyed December 2015-March 2016, and in Scotland, Northern Ireland and Wales July-October 2016. Respondents were asked to indicate on the survey their willingness to participate in a telephone interview. COREQ guidelines were followed [23].

\section{Data collection}

\section{Sampling}

Participants were selected for interview following survey completion. A purposive sampling framework was developed, stratified by treatment group (radical prostatectomy, external beam radiotherapy. brachytherapy, androgen deprivation therapy, and active surveillance / watchful waiting). We also purposively included a range of men who indicated experience of either no problems or one or more physical (e.g. urinary incontinence, bowel problems and erectile dysfunction) and emotional problems (e.g. anxiety/depression), as well as men from Black, Asian and Minority Ethnic groups and self-identified sexualities. 149 men were interviewed. Data reported here came from a subsample $(n=24,16.1 \%)$ of this larger interview dataset comprising all men in the subsample with advanced hormone-responsive stage IV PCa. 


\section{Interviews}

Four experienced researchers (LM, JN, CR, RW) conducted semi-structured telephone interviews, lasting approximately one hour. Interviewers came from broad disciplinary backgrounds including nursing and social sciences, and included one male (RW). The LAPCD clinical and scientific advisory group (CSAG) and patient user advisory groups (UAGs) informed the topic guide development as did our previous metasyntheses $[24,25,14]$. The interview topic guide (online resource 1 ) included questions regarding men's health care experiences and the psychosocial and physical impact of PCa. Open-ended questions and prompts were used.

\section{Analysis}

Interviews were transcribed verbatim, then managed using Nvivo v.11 [26]. Thematic analysis, using the seven stages of the framework approach [27], was employed for all men interviewed for the LAPCD study. The first stage involved familiarisation, whereby researchers became immersed in the data and aware of key ideas and recurrent themes. Following each interview, researchers' summarised key issues discussed and shared these amongst the research team for discussion. Five interview transcripts were initially independently coded (EW, RW, CR, LM and JN), and discussed at team meetings, with input from the patient UAG and a thematic coding framework of emerging themes was developed. As the analysis emerged, following subsequent interviews, this thematic coding framework (online resource 2 ) was iteratively refined. Analysis was both inductive and deductive, as the coding framework was primarily informed by team discussions but also used themes from the topic guide. The complete dataset was then indexed, identifying data that corresponded to particular themes. Double coding in Nvivo11 was conducted by three authors (CR, EW and RW) on $10 \%$ of interviews, with final Kappa scores of $\geq 80 \%$ across all themes for all researchers. Indexed data was then arranged in charts/matrices of themes, and key ideas and themes summarized in the charts/matrices with relationships between them identified. Following this process, we were able to determine distinctive or noteworthy subsamples for more in depth analysis as presented here for the sub-sample of men with hormone-responsive advanced prostate cancer. Analysis of the subsample involved collation of all coding frames of all men with advanced PCa. Men with advanced hormone-responsive PCa were included but those with castrate-resistant PCa were removed from the subsample as there were only two men in this sub-sample which was not enough to determine whether their experiences were convergent or divergent from the other hormone-responsive men. Sub sample analysis involved exploration of within-group convergence and divergence. Themes were further developed from the data, and discussed at team meetings, with input from two patient UAG members, and our CSAG members. Data saturation was achieved. Framework matrices enabled checks to see where the subsample differed from the main sample of men with earlier stage (I-III) PCa.

\section{Findings}

Sample characteristics are presented (see Table 1). All were currently receiving ADT. Nine (37.5\%) reported they were currently on clinical trials. The overarching concept from the interview data was 'enablers and barriers to living well with advanced hormone-responsive $P C C^{\prime}$ '.

Enablers and Barriers to living well with advanced hormone-responsive PCa 
Most men perceived they had a relatively good QoL and felt they were able to 'live well' with PCa, influenced by a number of factors. Barriers to living well with PCa were often the converse of these factors and also included: more troublesome PCa or comorbidity-related symptoms, and stronger perceptions of loss and restriction. Across the sample there appeared to be a continuum in terms of men's perceived QoL, with a few men perceiving they had a poor QoL (see Figure 1).

\section{[INSERT FIG 1]}

\section{Connectedness to others}

Feeling emotionally closer to others, particularly to partners, family and friends, and having a greater appreciation of relationships helped give men's lives meaning, which may have enhanced QoL. Despite loss of libido and sexual functioning, some men reported that over time they felt their spousal relationship had been strengthened.

I have absolutely no sexual urges at all. But it's been really interesting how my relationship with my wife has actually grown up as a result. .... we are in a good place; things have changed, but in fact we've almost realised we don't really need it [sex] (56 years, married)

Conversely, a few men described areas where their connectedness to others felt threatened, which appeared to impact on QoL. A few reported struggling with feeling inadequate as a sexual partner, feeling a burden on their spouses, or the loss of a sense of connection to peers (' [friend] basically told me to go away, he didn't want to discuss it [PCa]' 67 years, married).

You feel inadequate. I mean [wife's] 58, and I love her very much. Every day I apologise and say I'm sorry for what we're going through. And she said is it your fault? I said I don't know. (67 years, married)

\section{Engagement in meaningful activities}

Activities such as walking, gardening or seeing grandchildren, were perceived as influencing a good QoL, and also brought meaning to their lives. Some described being just as active, or even more so, in these pastimes than they had been before $\mathrm{PCa}$, and talked about trying to make the most of the present as a result of their diagnosis and prognosis. A few even felt they were 'enjoying life more' following PCa.

I'm still almost as active as I've always been. I still do DIY, some gardening, play golf. I'm hoping to be so for some years to come. (64 years, married)

However, participation in activities was more limited for some following PCa diagnosis ('I can't really do exercise because I'm just tired now' 56 years, married). Those who reported a greater symptom burden from PCa treatment and/or comorbidities experienced a greater sense of restriction in their ability to participate in valued activities. For a few, pain and fatigue meant struggling with staying active and being engaged in day-to-day life. Sometimes this led to forced early retirement, which contributed to feelings of loss over their pre-PCa lives.

Is this life that I'm living, is this a full life? It doesn't feel it to me, it feels about half. (60 years, married) 


\section{Adjustment strategies}

Various coping strategies to adjust were described. Adjustments such as limiting the duration/intensity of activities enabled some to continue with normal activities, including work, despite fatigue and reduced stamina. Adjusting to urinary or bowel incontinence involved planning ahead by gaining familiarity with local toilets, and making adjustments to diet or alcohol intake.

I need to get out; I can't be stuck in the house all day doing nothing. So I've got a little dog here, I take him for walks when I'm up to it. I go out for a meal, usually a place I know, so I know where the toilets are. (46 years, married)

While a few men described ongoing struggles to adjust to the changes to their sexual and masculine identities and relationships following sexual dysfunction, many men (with partners) reported strategies of reappraisal of the importance of sexual activity ('small price to pay for still being alive', 72 years, married), gradual acceptance ('as time has gone on, it doesn't bother me as much now' 68 years, married) and attempts at maintaining intimacy. Similarly, while a few men held ongoing concerns surrounding dissatisfaction over body feminisation changes brought about by ADT, such as reduced testicle size, breast enlargement or diminished muscle mass, others described developing flexibility in their beliefs regarding masculinity, and reframed changes positively.

You have to re-evaluate yourself as a man. But that doesn't mean to say you can't be a man... it's amazing how switching off your testosterone supply can make you feel better about life! I feel softer... perhaps more in touch with my feminine side (56 years, married)

To manage the emotional impact, men discussed strategies of acceptance, keeping busy, positive thinking, making social comparisons to others worse off, using humour and, for some, taking antidepressant medication. Men generally preferred informal conversations with peers or spouses, rather than support groups. However, a few men maintained a stoical and silent approach to managing their emotional distress or physical problems, and struggled to raise these issues with health professionals.

\section{Having resources to help self-manage}

Men's resources appeared to impact on their QoL, particularly social, cognitive or financial resources. Men often reported the benefits of spousal, family and peer support at helping them manage PCa.

"I feel healthy enough in myself, we've got a good circle of friends, I feel really well supported" (71 years, married)

Men with family living a distance away could struggle, as could those who reported little social support. Those with lower financial resources struggled to afford holidays, leisure activities or even simple hobbies, while others could afford and enjoy such activities, which they felt impacted positively on QoL. In terms of cognitive resources, most reported feeling confident and motivated to manage PCa.

I feel I'm on top of things myself. It hasn't become a problem; it hasn't become restrictive so life goes on as much as it can as normal. (57 years, married) 
However, a few struggled with motivation to stay active and have a healthy diet, particularly if symptoms such as fatigue were problematic.

\section{Managing uncertainties}

Following the shock of diagnosis, some felt they were becoming better at tolerating and managing PCa-related uncertainties over time, and appeared hopeful and optimistic about the future. This was influenced by a determination to enjoy life, and an emphasis on the need for making short-term rather than long-term goals.

I'm obviously not confident of a lengthy life but I'm quietly confident I have a few years left. The sell by date they've given me I've passed so every day now is a bonus (77 years, In a relationship)

However, others struggled with uncertainties surrounding the future. In particular men could struggle with uncertainty surrounding PSA testing and some did not trust PSA testing as a reliable indicator of recurrence. A few were not given information on future treatments, which contributed to a sense of loss of control over the future.

\section{Support, communication and information from health care professionals}

Many participants felt their supportive care was excellent, and those on a clinical trial appreciated the extra support they received.

'Being on that trial has meant I've just had fantastic care' (56 years, married)

However, a few wanted more psychological support and reassurance, particularly more frequent follow-up calls. Some wished health professionals were more proactive at asking about sensitive issues, such as sexual dysfunction.

I think would feel so great if you got one call, even once a month, to say how are you? Any new symptoms? Or how do you feel? (67 years, married)

Men's QoL appeared to be positively impacted by receiving information and effective communication at diagnosis and at follow-up, particularly on what to expect regarding symptoms and potential life expectancy. Having realistic expectations regarding prognosis helped men prepare themselves and motivated them to make the most of life.

[Consultant's] extremely good, he tells you the truth. If you ask him a question you will get a straight answer (71 years, married)

Some felt however, that they were not given enough information regarding their PSA result. A few participants described confusion and uncertainty over their care or treatment regimen. In particular, one participant had encountered unclear language regarding his prognosis at diagnosis, and had associated the word 'terminal' with meaning he had only a few months to live.

When they first diagnosed me, I thought six months, gone. Because that's what you hear about cancer. That's another thing that needs to be explained, that you're not going to die in six months, as far as we are aware (67 years, married) 


\section{Discussion}

While some previous literature has highlighted that men with advanced PCa have poorer QoL outcomes [28,29], and are at increased risk of distress [30,31], our analysis focuses on the strategies that men with advanced hormone-responsive PCa employ to adjust and 'live well'. Across the sample, we identified a continuum in terms of men's perceived QoL (Figure 1) with most men perceiving their QoL to be good. Our findings increase understanding of the key enablers and barriers to living well with advanced hormone responsive PCa. This is important in light of the increasing numbers of men with advanced PCa who are living longer with their diagnosis and in a hormone-sensitive treatment phase. Some of the themes we identified have previously been shown in men with advanced PCa, including the importance of connectedness to others $[17,11,14]$, and a sense of purpose [11]. Our findings highlight how being able to engage in meaningful activities was particularly important for men's QoL, even if this was unstructured simple activities such as walking. Similar to our findings, it has previously been shown that a lower income and greater symptom burden are associated with poorer QoL in men with PCa [32,33].

Our qualitative findings help explain our population-based LAPCD survey findings [34], which indicated while men with advanced PCa report more treatment-related problems, such as with hormonal functioning, overall QoL was not markedly different to men with earlier stage PCa [33,34]. Many themes presented were not markedly different from those for men with localised disease in our total sample of interviewed men. However, men with advanced PCa more often had ADT symptoms to manage. This was also echoed in our metasynthesis [14]. It would appear that many men with advanced $\mathrm{PCa}$ in our sample seemed to demonstrate resilience. An existing resilience theory - sense of coherence (SOC) theory [35], can help interpret our findings, as SOC theory explains how some people can maintain wellbeing despite adversity. Distress in cancer patients has been shown to be associated with a low SOC [36]. Three main components comprise a SOC; a sense of meaningfulness, manageability and comprehensibility, impacted by a person's resources (e.g. selfefficacy, social support, financial resources) $[35,37]$. Our themes resonate with components of this theory, particularly the concepts of sense of meaningfulness and manageability, and the role of resources. Having a sense of comprehensibility was also important, as our findings indicate that participants could struggle if they were uncertain or confused about future treatments or PSA results.

Having a sense of uncertainty has also previously been a prominent theme [14]. However, our findings show men's ability to manage uncertainty over time, and the level of information and communication provided by health professionals regarding prognosis and treatment seemed to have a positive influence on QoL. An individual's appraisal of uncertainty may also be important at influencing whether men view illness as a threat or an opportunity [38]. As shown previously, men who adopt healthier lifestyles or reconnected with others sometimes reported life was better than before PCa diagnosis[14]. While many previous studies in our metasynthesis [14] highlighted the difficulties that men face with regards to sexual dysfunction; our findings focus on the strategies that men adopt to overcome them. Most men appeared to have adjusted to sexual dysfunction and accepted that this aspect of their lives had changed. This may be reflective of the advanced prognosis of our sample, as the majority of previous studies have focused on men with earlier stage disease.

\section{Implications}


Health professionals could encourage men to start or continue participating in meaningful activities even if in a more limited way than before, and promote and identify resources to support selfmanagement. Activity-based interventions, such as walking or interest groups, warrant further investigation, as research shows the benefits of keeping active and engaged [39]. Social prescribing, of social, community or non-medical activities by general practitioners, may be a cost-effective way of getting men involved and improving QoL, however further studies in this patient group are warranted[40]. Future studies could also examine whether eHealth interventions might be effective for men who struggle to attend groups due to a high symptom burden. Meaning-focused coping interventions, shown to help patients manage uncertainty regarding the future, might also be worth exploration for men with advanced PCa [41].

Findings highlight the value of clear information from the clinician, in terms of prognosis, the implications of PSA test results, and treatment planning. It is important that health professionals take care in the language they use and avoid using the word 'terminal' for men with advanced PCa with a reasonable prognosis. This is important as misperceptions of medical terminology has been shown in the general population, of whom most are not able to distinguish between the terms 'terminal' or 'advanced' [42]. It might be useful for men to be made aware at diagnosis that many men living with advanced PCa are able to live for many years and experience a good QoL. However, it is important for health professionals to assess how much information men want regarding their prognosis, as not all men may wish to know this. Future research could further investigate how prognosis is discussed during appointments.

It is also important that health professionals consider the impact of men's constructions of hegemonic masculinity and how this may impact on their approach to help-seeking for physical or psychological problems, as a few men struggled to raise these issues, also shown previously [43]. Screening tools may be useful to identify men who are reluctant to discuss their concerns, such as the Patient Concerns Inventory. Health professionals could use such instruments as a discussion tool during appointments.

\section{Limitations}

Men in our sample were 18-42 months post diagnosis and were on ADT. A third were part of a clinical trial, which may mean they had a more positive experience of healthcare, and a disproportionate number were younger ( $<65$ years). Our findings therefore provide a snapshot of the experiences of men who are relatively close to diagnosis with hormone-responsive PCa, and may not be reflective of the experiences of all men with stage IV disease. As the majority of men treated with ADT will progress to metastatic castrate-resistant PCa, associated with a greater symptom burden $[44,45]$, men from this group require further study.

\section{Conclusions}

Findings indicate key dimensions that seemed to influence QoL and men's ability to 'live well' with advanced hormone-responsive PCa. This may also have relevance for patients living with other types of advanced cancer. Further research is required to develop and test interventions for men with a poorer QoL.

\section{Words: 3493}




\section{Compliance with ethical standards}

Conflict of Interest statement: The authors declare that they have no conflicts of interest.

Research involving Human Participants: All procedures performed in studies involving human participants were in accordance with the ethical standards of the institutional and/or national research committee (Newcastle/North Tyneside Research Ethics Committee (15/NE/0036), Health Research Authority Confidentiality Advisory Group (15/CAG/0110), NHS Scotland Public Benefit and Privacy Panel (0516-0364), Northern Ireland Research Ethics Office (16/NI/0073)) and with the 1964 Helsinki declaration and its later amendments or comparable ethical standards.

Informed consent: Informed consent was obtained from all individual participants included in the study.

Author contributions: EW, RW, PW, AG, AG \& HB contributed to the study conception and design. Data collection and analysis were performed by LM, JN, CR, JB, RW and EW. The first draft of the manuscript was written by LM and all authors commented on previous versions of the manuscript. All authors read and approved the final manuscript.

Funding statement: The Life After Prostate Cancer Diagnosis study was funded by the Movember Foundation, in partnership with Prostate Cancer UK, as part of the Prostate Cancer Outcomes programme, grant number BO26/MO.

Data availability statement: The datasets generated and/or analysed in the current study are not available publicly as eligible patients were informed at the time of the survey their data would be stored securely and confidentially.

\section{References}

1. Cancer Research UK (2018) Prostate cancer incidence statistics.

https://www.cancerresearchuk.org/health-professional/cancer-statistics/statistics-by-cancertype/prostate-cancer/incidence\#heading-Three. Accessed 12/11/2018 2018

2. Cancer Research UK (2018) Prostate cancer survival statistics https://www.cancerresearchuk.org/health-professional/cancer-statistics/statistics-by-cancertype/prostate-cancer/survival\#heading-Three. Accessed 12/11/2018 2018

3. National Institute For Health and Care Excellence (2019) Prostate Cancer: Diagnosis and Management [NG131]. https://www.nice.org.uk/guidance/ng131. Accessed 23rd May 2019 4. James ND, de Bono JS, Spears MR, Clarke NW, Mason MD, Dearnaley DP, Ritchie AWS, Amos CL, Gilson C, Jones RJ, Matheson D, Millman R, Attard G, Chowdhury S, Cross WR, Gillessen S, Parker CC, Russell JM, Berthold DR, Brawley C, Adab F, Aung S, Birtle AJ, Bowen J, Brock S, Chakraborti P, Ferguson C, Gale J, Gray E, Hingorani M, Hoskin PJ, Lester JF, Malik ZI, McKinna F, McPhail N, MoneyKyrle J, O'Sullivan J, Parikh O, Protheroe A, Robinson A, Srihari NN, Thomas C, Wagstaff J, Wylie J, Zarkar A, Parmar MKB, Sydes MR (2017) Abiraterone for Prostate Cancer Not Previously Treated with Hormone Therapy. NEJM 377 (4):338-351. doi:10.1056/NEJMoa1702900

5. Watson E, Shinkins B, Frith E, Neal D, Hamdy F, Walter F, Weller D, Wilkinson C, Faithfull S, Wolstenholme J, Sooriakumaran P, Kastner C, Campbell C, Neal R, Butcher H, Matthews M, Perera R, Rose $P$ (2016) Symptoms, unmet needs, psychological well-being and health status in survivors of 
prostate cancer: implications for redesigning follow-up. BJU int 117 (6B):E10-19.

doi:10.1111/bju.13122

6. Nead KT, Sinha S, Yang DD, Nguyen PL (2017) Association of androgen deprivation therapy and depression in the treatment of prostate cancer: A systematic review and meta-analysis. Urol Oncol 35 (11):664 e661-664 e669. doi:10.1016/j.urolonc.2017.07.016

7. Fang F, Keating NL, Mucci LA, Adami HO, Stampfer MJ, Valdimarsdottir U, Fall K (2010) Immediate risk of suicide and cardiovascular death after a prostate cancer diagnosis: cohort study in the United States. J Natl Cancer Inst 102 (5):307-314. doi:10.1093/jnci/djp537

8. van Leeuwen PJ, Schröder FH (2010) Increased risk of suicide after prostate cancer diagnosis. Nature Reviews Urology 7:369. doi:10.1038/nrurol.2010.83

9. Gentili C, McClean S, Hackshaw-McGeagh L, Bahl A, Persad R, Harcourt D (2019) Body image issues and attitudes towards exercise amongst men undergoing androgen deprivation therapy (ADT) following diagnosis of prostate cancer. Psycho-Oncology 0 (0). doi:10.1002/pon.5134 10. Charalambous A, Kouta C (2016) Cancer Related Fatigue and Quality of Life in Patients with Advanced Prostate Cancer Undergoing Chemotherapy. BioMed Res Int 2016:11. doi:10.1155/2016/3989286

11. Levy A, Cartwright T (2015) Men's strategies for preserving emotional well-being in advanced prostate cancer: An interpretative phenomenological analysis. Psychol Health 30 (10):1164-1182. doi:10.1080/08870446.2015.1040016

12. Shen MJ, Nelson CJ, Peters E, Slovin SF, Hall SJ, Hall M, Herrera PC, Leventhal EA, Leventhal H, Diefenbach MA (2015) Decision-making Processes among Prostate Cancer Survivors with Rising PSA Levels: Results from a Qualitative Analysis. Med Decis Making 35 (4):477-486.

doi:10.1177/0272989X14558424

13. Stapleton S, Pattison N (2015) The lived experience of men with advanced cancer in relation to their perceptions of masculinity: a qualitative phenomenological study. J Clin Nurs 24 (7-8):10691078. doi:10.1111/jocn.12713

14. Rivas C, Matheson L, Nayoan J, Glaser A, Gavin A, Watson E, Wagland R (Submitted) Men's transformations following a prostate cancer diagnosis and opportunities for intervention: a metaethnographic study.

15. Grunfeld EA, Halliday A, Martin P, Drudge-Coates L (2011) Andropause syndrome in men treated for metastatic prostate cancer: a qualitative study of the impact of symptoms. Cancer Nurs 35 (1):6369. doi:10.1097/NCC.0b013e318211fa92

16. Sartor O, Flood E, Beusterien K, Park J, Webb I, MacLean D, Wong BJO, Mark Lin H (2015) HealthRelated Quality of Life in Advanced Prostate Cancer and Its Treatments: Biochemical Failure and Metastatic Disease Populations. Clin Genitourin Cancer 13 (2):101-112.

doi:10.1016/j.clgc.2014.08.001

17. Lepherd L (2013) Spirituality in men with advanced prostate cancer: "it's a holistic thing ... it's a package". J Holist Nurs 32 (2):89-101; quiz 102-103. doi:0898010113504492 [pii]

10.1177/0898010113504492

18. Carlander I, Ternestedt BM, Sahlberg-Blom E, Hellstrom I, Sandberg J (2011) Four aspects of selfimage close to death at home. Int J Qual Stud Health Well-being 6 (2). doi:10.3402/qhw.v6i2.5931 19. Lindqvist O, Rasmussen BH, Widmark A (2008) Experiences of symptoms in men with hormone refractory prostate cancer and skeletal metastases. Eur J Oncol Nurs 12 (4):283-290.

doi:10.1016/j.ejon.2008.03.003

20. Lindqvist O, Widmark A, Rasmussen BH (2006) Reclaiming wellness - Living with bodily problems, as narrated by men with advanced prostate cancer. Cancer Nurs 29 (4):327-337.

doi:10.1097/00002820-200607000-00012

21. Chambers SK, Hyde MK, Laurie K, Legg M, Frydenberg M, Davis ID, Lowe A, Dunn J (2018) Experiences of Australian men diagnosed with advanced prostate cancer: a qualitative study. BMJ Open 8 (2):e019917. doi:10.1136/bmjopen-2017-019917 
22. Downing A, Wright $P$, Wagland $R$, Watson $E$, Kearney $T$, Mottram R, Allen $M$, Cairnduff $V$, McSorley O, Butcher H, Hounsome L, Donnelly C, Selby P, Kind P, Cross W, Catto JW, Huws D, Brewster DH, McNair E, Matheson L, Rivas C, Nayoan J, Horton M, Corner J, Verne J, Gavin A, Glaser AW (2016) Life after prostate cancer diagnosis: protocol for a UK-wide patient-reported outcomes study. BMJ Open 6 (12):e013555. doi:10.1136/bmjopen-2016-013555

23. Tong A, Sainsbury P, Craig J (2007) Consolidated criteria for reporting qualitative research (COREQ): a 32-item checklist for interviews and focus groups. Int J Qual Health Care 19 (6):349-357. doi:10.1093/intqhc/mzm042

24. Matheson L, Watson EK, Nayoan J, Wagland R, Glaser A, Gavin A, Wright P, Rivas C (2017) A qualitative metasynthesis exploring the impact of prostate cancer and its management on younger, unpartnered and gay men. Eur J Cancer Care 26 (6). doi:10.1111/ecc.12676

25. Rivas C, Matheson L, Nayoan J, Glaser A, Gavin A, Wright P, Wagland R, Watson E (2016) Ethnicity and the prostate cancer experience: a qualitative metasynthesis. Psycho-Oncology 25 (10):11471156. doi:10.1002/pon.4222

26. QSR International Pty Ltd (2016) NVivo qualitative data analysis Software: version 11.

27. Gale NK, Heath G, Cameron E, Rashid S, Redwood S (2013) Using the framework method for the analysis of qualitative data in multi-disciplinary health research. BMC Med Res Methodol 13:117. doi:10.1186/1471-2288-13-117

28. Rosenfeld B, Roth AJ, Gandhi S, Penson D (2004) Differences in health-related quality of life of prostate cancer patients based on stage of cancer. Psycho-Oncology 13 (11):800-807. doi:10.1002/pon.797

29. Torvinen S, Färkkilä N, Sintonen H, Saarto T, Roine RP, Taari K (2013) Health-related quality of life in prostate cancer. Acta Oncol 52 (6):1094-1101. doi:10.3109/0284186X.2012.760848

30. Wright $P$, Wilding S, Watson E, Downing A, Selby P, Hounsome L, Wagland R, Brewster DH, Huws D, Butcher H, Mottram R, Kearney T, Allen M, Gavin A, Glaser A (2019) Key factors associated with social distress after prostate cancer: Results from the United Kingdom Life after Prostate Cancer diagnosis study. Cancer Epidemiol 60:201-207. doi:10.1016/j.canep.2019.04.006

31. Wilding S, Downing A, Wright $P$, Selby $P$, Watson $E$, Wagland R, Donnelly DW, Hounsome $L$, Butcher H, Mason M, Henry A, Gavin A, Glaser AW (2019) Cancer-related symptoms, mental wellbeing, and psychological distress in men diagnosed with prostate cancer treated with androgen deprivation therapy. Qual Life Res 28 (10):2741-2751. doi:10.1007/s11136-019-02212-x

32. Chambers SK, Ng SK, Baade P, Aitken JF, Hyde MK, Wittert G, Frydenberg M, Dunn J (2017) Trajectories of quality of life, life satisfaction, and psychological adjustment after prostate cancer. Psycho-Oncology 26 (10):1576-1585. doi:10.1002/pon.4342

33. Sarah Wilding, Amy Downing, Penny Wright, Peter Selby, Eila Watson, Richard Wagland, David Donnelly, Malcolm Mason, Ann Henry, Anna Gavin, Glaser AW (In preparation ) Cancer-related symptoms, mental well-being and psychological distress in men diagnosed with prostate cancer treated with Androgen Deprivation Therapy.

34. Downing A, Wright P, Hounsome L, Selby P, Wilding S, Watson E, Wagland R, Kind P, Donnelly D, Butcher $H$ (2018) Quality of life in men living with advanced and localised prostate cancer: A United Kingdom population-wide patient-reported outcome study of 30,000 men. Lancet Oncol

35. Antonovsky A (1979) Health, Stress and Coping. Jossey-Bass,, San Fransisco

36. Winger JG, Adams RN, Mosher CE (2016) Relations of meaning in life and sense of coherence to distress in cancer patients: a meta-analysis. Psycho-oncology 25 (1):2-10. doi:10.1002/pon.3798 37. Antonovsky A (1987) Unraveling the Mystery of Health. How People Manage Stress and Stay Well. Jossey-Bass,, San Fransisco, London

38. Mishel MH (1990) Reconceptualization of the uncertainty in illness theory. Image: The Journal of Nursing Scholarship 22 (4):256-262

39. Bourke L, Gilbert S, Hooper R, Steed LA, Joshi M, Catto JWF, Saxton JM, Rosario DJ (2014) Lifestyle Changes for Improving Disease-specific Quality of Life in Sedentary Men on Long-term 
Androgen-Deprivation Therapy for Advanced Prostate Cancer: A Randomised Controlled Trial. European Urology 65 (5):865-872. doi:10.1016/j.eururo.2013.09.040

40. Husk K, Blockley K, Lovell R, Bethel A, Lang I, Byng R, Garside R (2019) What approaches to social prescribing work, for whom, and in what circumstances? A realist review. Health Soc Care Community n/a (n/a). doi:10.1111/hsc.12839

41. Vehling S, Philipp R (2018) Existential distress and meaning-focused interventions in cancer survivorship. Current Opinion in Supportive and Palliative Care 12 (1):46-51.

doi:10.1097/spc.0000000000000324

42. Kim SH, Shin DW, Kim SY, Yang HK, Nam E, Jho HJ, Ahn E, Cho BL, Park K, Park J-H (2016) Terminal Versus Advanced Cancer: Do the General Population and Health Care Professionals Share a Common Language? Cancer Res Treat 48 (2):759-767. doi:10.4143/crt.2015.124

43. Courtenay WH (2000) Constructions of masculinity and their influence on men's well-being: a theory of gender and health. Soc Sci Med 50 (10):1385-1401

44. Carter N, Bryant-Lukosius D, DiCenso A, Blythe J, Neville AJ (2011) The supportive care needs of men with advanced prostate cancer. Oncol Nurs Forum 38 (2):189-198. doi:10.1188/11.ONF.189198.

45. Jenkins VA, Fallowfield $\amalg$ (2016) No man's land: information needs and resources of men with metastatic castrate resistant prostate cancer. Support Care Cancer 24 (11):4471-4473.

doi:10.1007/s00520-016-3358-0 